Pacific Journal of Mathematics

ON A THEOREM OF HAYMAN CONCERNING TH
DERIVATIVE OF A FUNCTION OF BOUNDED

Patrick Robert A herN 


\title{
ON A THEOREM OF HAYMAN CONCERNING THE DERIVATIVE OF A FUNCTION OF BOUNDED CHARACTERISTIC
}

\section{PATRICK AHERN}

\begin{abstract}
W. Hayman [On Nevanlinna's second theorem and extensions, Rend. Circ. Mat. Palermo, Ser. II, II (1953).] has given sufficient conditions on a function, $f$, of bounded characteristic in the unit disc, in order that $f^{\prime}$ also have bounded characteristic. In this paper it is shown that one of these conditions is also necessary for the conclusion of the theorem to hold.
\end{abstract}

Let $U$ be the open unit disc in the complex plane and let $T$ be its boundary. It is well known that there are functions $f$, that are bounded and holomorphic in $U$, such that $f^{\prime} \notin N(U)$. Here $N(U)$ is the Nevanlinna class. In fact, O. Frostman, [1, Théoreme IX], has shown that there are Blaschke products with some degree of "smoothness" whose derivatives fail to lie in $N(U)$. More precisely, he shows that there is a Blaschke product $B$, whose zeros $\left\{a_{n}\right\}$ satisfy the condition,

$$
\sum_{n}\left(1-\left|a_{n}\right|\right)^{\alpha}<\infty, \text { for all } \alpha>\frac{1}{2},
$$

but $B^{\prime} \notin N(U)$. In Frostman's example, every point of $T$ is a limit point of the sequence $\left\{a_{n}\right\}$.

W. Hayman, [2, Theorem IV], has proved a result in the positive direction. A function $f$, that is holomorphic in a bounded domain $D$, is said to be of order $K$ if, for every complex number $a$, the number of solutions of the equation, $f(z)=a$, that are at a distance of at least $\varepsilon$ from the boundary of $D$ is at most $C \varepsilon^{-K}$, for some constant $C$. $C$ may depend on $a$ but not on $\varepsilon$. We say $f$ has finite order if it has order $K$ for some $K$. Now let $D$ be a bounded open set such that $U \subseteq D$, and let $D \cap T=\bigcup_{n} I_{n}$, where $I_{n}=\left\{e^{i 0}: \alpha_{n}<\theta<\beta_{n}\right\}$.

THEOREM A (Hayman). Suppose that

(i ) (a) $\sum_{n}\left(\beta_{n}-\alpha_{n}\right)=2 \pi$

(b) $\sum_{n}\left(\beta_{n}-\alpha_{n}\right) \log 1 /\left(\beta_{n}-\alpha_{n}\right)<\infty$.

(ii) there are constants $\varepsilon, C>0$ such that if $\alpha_{n}<\theta<\beta_{n}$, then

$$
\operatorname{dist}\left(e^{i \theta}, \partial D\right) \geqq \varepsilon\left(\left|\theta-\alpha_{n}\right|\left|\theta-\beta_{n}\right|\right)^{c} .
$$

(iii) $f$ is holomorphic and of finite order in $D$ and $f \in N(U)$. 
Then $f^{(k)} \in N(U)$ for $k=1,2,3, \cdots$.

The conditions (i)(a) and (i)(b) just mean that the set $E=T \backslash \bigcup_{n} I_{n}$ is what is usually called a Carleson set.

In [4], P. Kennedy investigates the necessity of condition (i)(b). He shows that if (i)(a) holds but

$$
\varlimsup_{n \rightarrow \infty}\left(\sum_{j=n}^{\infty}\left(\beta_{j}-\alpha_{j}\right)\right) \log \frac{1}{\left(\beta_{n}-\alpha_{n}\right)}=\infty,
$$

then there is a bounded open set $D \supseteqq U$ such that $D \cap T=\bigcup_{n} I_{n}, I_{n}=$ $\left\{e^{i \theta}: \alpha_{n}<\theta<\beta_{n}\right\}$, and a function $f$ that is bounded and holomorphic in $D$ such that $f^{\prime} \notin N(U)$. He observes that condition $\left(^{*}\right)$ does not follow from the condition

$$
\sum_{n}\left(\beta_{n}-\alpha_{n}\right) \log \frac{1}{\beta_{n}-\alpha_{n}}=\infty,
$$

and writes that "there is still a gap between the positive information given by Hayman's theorem and the negative information" given by his example.

In this note we close the gap by showing that condition (i)(b) is the right one. Our example is a Blaschke product that retains the same degree of smoothness as the one of Frostman's example.

THEOREM. To each sequence of arcs $\left\{I_{n}\right\}, I_{n}=\left\{e^{i \theta}: \alpha_{n}<\theta<\beta_{n}\right\}$, that satisfies (i)(a) but not (i)(b), there corresponds a Blaschke product, $B$, whose zero sequence, $\left\{a_{n}\right\}$, clusters only on $T \backslash \bigcup_{n} I_{n}$, such that $B^{\prime} \notin N(U)$ and $\sum\left(1-\left|a_{n}\right|\right)^{\alpha}<\infty$ for all $\alpha>1 / 2$. Moreover, there is a bounded open set $D$, such that $D \supseteqq U, D \cap T=\cup_{n} I_{n}, D$ satisfies condition (i)(c) with $C=2$, and $B$ extends to be bounded and of order 1 in $D$.

Proof. Let $\varepsilon_{n}=\beta_{n}-\alpha_{n}$. We are assuming that $\sum_{n} \varepsilon_{n} \log \left(1 / \varepsilon_{n}\right)=$ $\infty$. We may choose numbers $\delta_{n}, 0<\delta_{n}<1$, such that $\lim _{n \rightarrow \infty} \delta_{n}=0$, and $\sum_{n} \delta_{n} \varepsilon_{n} \log 1 / \varepsilon_{n}=\infty$. Now define $d_{n}=\varepsilon_{n}^{2-\delta_{n}}$ and $c_{n}=\left(1-d_{n}\right) e^{i \alpha_{n}}$ and $\gamma_{n}=\left(1-d_{n}\right) e^{i \beta_{n}}$. Let $B$ be the Blascke product whose zeros are $\left\{c_{n}\right\} \cup\left\{\gamma_{n}\right\}$. The zeros of $B$ cluster only on the set $E=T \backslash \bigcup_{n} I_{n}$ so $B$ is holomorphic on $I_{n}$ for every $n$. We calculate that

$$
B^{\prime}(z)=B(z)\left\{\sum_{n} \frac{1-\left|c_{n}\right|^{2}}{\left(z-c_{n}\right)\left(1-\bar{c}_{n} z\right)}+\sum_{n} \frac{1-\left|\gamma_{n}\right|^{2}}{\left(z-\gamma_{n}\right)\left(1-\bar{\gamma}_{n} z\right)}\right\}
$$

so that when $e^{i \theta} \in I_{n}$ we get

$$
e^{i \theta} B^{\prime}\left(e^{i \theta}\right)=B\left(e^{i \theta}\right)\left\{\sum_{k} \frac{1-\left|c_{k}\right|^{2}}{\left|e^{i \theta}-c_{k}\right|^{2}}+\sum_{k} \frac{1-\left|\gamma_{k}\right|^{2}}{\left|e^{i \theta}-\gamma_{k}\right|^{2}}\right\} .
$$


If $B^{\prime}$ were in $N(U)$ it would follow that

$$
\sum_{n} \int_{I_{n}} \log ^{+}\left(\sum_{k} \frac{1-\left|c_{k}\right|^{2}}{\left|e^{i \theta}-c_{k}\right|^{2}}\right) d \theta<\infty .
$$

Now,

$$
\begin{aligned}
\left|e^{i \theta}-c_{n}\right|^{2} & =\left(1-\left|c_{n}\right|\right)^{2}+4\left|c_{n}\right| \sin ^{2}\left(\frac{\theta-\alpha_{n}}{2}\right) \\
& \leqq d_{n}^{2}+\left(\theta-\alpha_{n}\right)^{2}
\end{aligned}
$$

and hence

$$
\frac{1-\left|c_{n}\right|^{2}}{\left|e^{i \theta}-c_{n}\right|^{2}} \geqq \frac{d_{n}}{d_{n}^{2}+\left(\theta-\alpha_{n}\right)^{2}}
$$

If $e^{i \theta} \in I_{n}$, then

$$
\begin{aligned}
\log ^{+}\left(\sum_{k} \frac{1-\left|c_{k}\right|^{2}}{\left|e^{i \theta}-c_{k}\right|^{2}}\right) & \geqq \log \left(\sum_{k} \frac{1-\left|c_{k}\right|^{2}}{\left|e^{i \theta}-c_{k}\right|^{2}}\right) \\
& \geqq \log \frac{1-\left|c_{n}\right|}{\left|e^{i \theta}-c_{n}\right|^{2}} \geqq \log \frac{d_{n}}{d_{n}^{2}+\left(\theta-\alpha_{n}\right)^{2}} .
\end{aligned}
$$

So we see that

$$
\begin{aligned}
\sum_{n} \int_{I_{n}} \log ^{+}\left(\sum_{k} \frac{1-\left|c_{k}\right|^{2}}{\left|e^{i \theta}-c_{k}\right|^{2}}\right) & \geqq \sum_{n} \int_{I_{n}} \log \frac{d_{n}}{d_{n}^{2}+\left(\theta-\alpha_{n}\right)^{2}} d \theta \\
& \geqq \sum_{n} \varepsilon_{n} \log \frac{d_{n}}{d_{n}^{2}+\varepsilon_{n}^{2}}
\end{aligned}
$$

Since $\delta_{n}<1$, we see that $d_{n}=\varepsilon_{n}^{2-\delta_{n}} \leqq \varepsilon_{n}$ (assuming $\varepsilon_{n}<1$ ), so

$$
\log \frac{d_{n}}{d_{n}^{2}+\varepsilon_{n}^{2}} \geqq \log \frac{d_{n}}{2 \varepsilon_{n}^{2}}=\log \frac{1}{2 \varepsilon_{n}^{\delta_{n} n}}=\log \frac{1}{2}+\delta_{n} \log \frac{1}{\varepsilon_{n}} .
$$

Hence,

$$
\sum_{n} \int_{I_{n}} \log ^{+}\left\{\sum_{k} \frac{1-\left|c_{k}\right|^{2}}{\left|e^{i \theta}-c_{k}\right|^{2}}\right\} d \theta \geqq 2 \pi \log \frac{1}{2}+\sum_{n} \delta_{n} \varepsilon_{n} \log \frac{1}{\varepsilon_{n}}=\infty .
$$

So $B^{\prime} \notin N(U)$. Also we see that

$$
\sum_{n}\left(1-\left|a_{n}\right|\right)^{\alpha}=2 \sum_{n} d_{n}^{\alpha}=\sum \varepsilon_{n}^{\left(2-\hat{o}_{n}\right) \alpha}<\infty
$$

if $\alpha>1 / 2$ because $\left(2-\delta_{n}\right) \alpha \geqq 1$ for all sufficiently large $n$.

It remains to construct the domain $D$. We have the inequality, 


$$
\begin{aligned}
\left|B\left(r e^{i \theta}\right)\right|^{2} & \geqq 1-\left(1-r^{2}\right)\left\{\sum_{k} \frac{1-\left|c_{k}\right|^{2}}{\left|1-r e^{i \theta} \bar{c}_{k}\right|^{2}}+\sum_{k} \frac{1-\left|\gamma_{k}\right|^{2}}{\left|1-r e^{i \theta} \bar{\gamma}_{k}\right|^{2}}\right\} \\
& \geqq 1-4\left(1-r^{2}\right)\left\{\sum_{k} \frac{1-\left|c_{k}\right|^{2}}{\left|r e^{i \theta}-\frac{1}{\bar{c}_{k}}\right|^{2}}+\sum_{k} \frac{1-\left|\gamma_{k}\right|^{2}}{\left|r e^{i \theta}-\frac{1}{\bar{\gamma}_{k}}\right|^{2}}\right\} .
\end{aligned}
$$

(We may assume $\left|c_{k}\right| \geqq 1 / 2,\left|\gamma_{k}\right| \geqq 1 / 2$.)

Now suppose $\alpha_{n} \leqq \theta \leqq\left(\alpha_{n}+\beta_{n}\right) / 2$ and $|z| \leqq 1$, then

$$
\left|B\left(r e^{i \theta}\right)\right|^{2} \geqq 1-\frac{4\left(1-r^{2}\right)}{\left|r e^{i \theta}-e^{i \alpha_{n}}\right|^{2}}\left(\sum_{k}\left(1-\left|c_{k}\right|^{2}\right)+\sum_{k}\left(1-\left|\gamma_{k}\right|^{2}\right)\right) .
$$

So, $\left|B\left(r e^{i \theta}\right)\right|^{2} \geqq 1 / 4$ if

$$
\frac{1-r^{2}}{\left|r e^{i \theta}-e^{i \alpha_{n}}\right|^{2}} \leqq \frac{3}{16} \frac{1}{\sum\left(1-\left|c_{k}\right|^{2}\right)+\sum\left(1-\left|\gamma_{k}\right|^{2}\right)}=C
$$

Note that $C$ is independent of $\theta$ and $n$. Similarly we see that if $\left(\alpha_{n}+\beta_{n}\right) / 2 \leqq \theta \leqq \beta_{n}$ and

$$
\frac{1-r^{2}}{\left|r e^{i \theta}-e^{i \beta}\right|^{2}} \leqq \frac{3}{16} \frac{1}{\sum_{k}\left(1-\left|c_{k}\right|^{2}\right)+\sum\left(1-\left|\gamma_{k}\right|^{2}\right)}=C,
$$

then $\left|B\left(r e^{i \theta}\right)\right|^{2} \geqq 1 / 4$. We may calculate that, for $C>0$,

$$
\left\{r e^{i \theta}: \frac{1-r^{2}}{\left|r e^{i \theta}-e^{i \lambda}\right|^{2}}<C\right\}=\left\{r e^{i \theta}:\left|r e^{i \theta}-\rho e^{i \lambda}\right|>1-\rho\right\},
$$

where $\rho=C /(1+C)$.

So, if

$$
\begin{aligned}
\Delta_{n}= & \left\{r e^{i \theta}: r \leqq 1, \alpha_{n}<\theta<\beta_{n},\left|r e^{i \rho}-\rho e^{i \alpha_{n}}\right|>1-\rho,\right. \\
& \text { and } \left.\left|r e^{i 0}-\rho e^{i \beta_{n}}\right|>1-\rho\right\} \text { and } \Delta=\bigcup_{n} \Delta_{n}, \text { then }|B(z)| \\
& \geqq 1 / 2, z \in \Delta .
\end{aligned}
$$

Now for $|z|>1, B(z)=1 / \overline{B(1 / \bar{z})}$, so $|B(z)| \leqq 2$ if $1 / \bar{z} \in \Delta$. Assuming, as we may, that $C<1$, we see that $\Gamma_{n}=\left\{z: 1 / \bar{z} \in \Delta_{n}\right\}=\{z:|z| \geqq 1$, $\left|z+\delta e^{i \alpha} n\right|<1+\delta$ and $\left.\left|z+\delta e^{i \beta_{n}}\right|<1+\delta\right\}$, where $\delta=C /(1-C)$. Finally, if we let $O=U \cup \cup_{n} \Gamma_{n}$ then $C$ is an open set and $|B(z)| \leqq 2$ for $z \in \mathcal{O}$.

Now we define a function

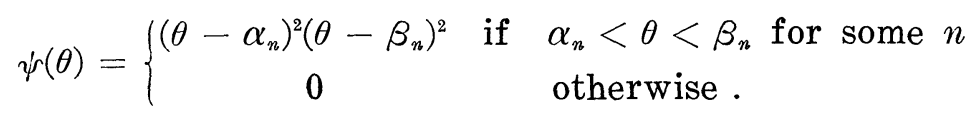

We check that $\psi^{\prime}(\theta)$ exists for all $\theta$ and that there is a constant $K$ such that 


$$
\left|\psi^{\prime}\left(\theta_{1}\right)-\psi^{\prime}\left(\theta_{2}\right)\right| \leqq K\left|\theta_{1}-\theta_{2}\right| \text {. }
$$

(See [4, Lemma 1] for a similar calculation.) For $\varepsilon>0$ we define $D_{\varepsilon}=\left\{r e^{i \theta}: r<e^{s \tau(\theta)}\right\}$. Then $D_{\varepsilon}$ satisfies condition (ii). of Theorem A with $C=2$. (Again, see [4, Lemma 2], for a similar calculation.) Also, it is not hard to that $D_{\varepsilon} \subseteq 0$ for all sufficiently small $\varepsilon>0$. So we fix some $\varepsilon>0$ such that $D_{\varepsilon} \leqq \varnothing$ and let $D=D_{\varepsilon}$. Since $D \subseteq$ $O, B$ is bounded in $D$. It remains to show that $B$ has order 1 in $D$. Let $\varphi: D \rightarrow U$ be a conformal map. Since $\psi^{\prime}$ satisfies a Lipschitz condition it follows from a theorem of Kellogg [3], that $\varphi^{\prime}$ extends to be continuous and nonvanishing on $\bar{D}$. From this we can conclude that there is a $\delta>0$ such that $1-|\varphi(z)| \geqq \delta \operatorname{dist}(z, \partial D)$ for all $z \in D$. Fix $a \in C$ and let $f=B-a$ and let $\left\{a_{n}\right\}$ be the zero sequence of $f$. Then $\left\{\varphi\left(a_{n}\right)\right\}$ is the zero sequence of the bounded function $f \circ \varphi^{-1}$ so $\sum_{n}\left(1-\left|\varphi\left(a_{n}\right)\right|\right)<\infty$ and hence $\sum_{n} \operatorname{dist}\left(a_{n}, \partial D\right)<\infty$. From this we may conclude that $B$ has order 1 in $D$.

As a final remark we point out that we may choose the $\operatorname{arcs} I_{n}$ in such a way that $E=T \backslash \bigcup_{n} I_{n}$ is a countable set with only one limit point, and such that (i)(b) fails. If we apply the theorem to this situation we get a Blaschke product $B$ whose zeros converge to a single point such that $B^{\prime} \notin N(U)$, while the zeros sequence, $\left\{a_{n}\right\}$, satisfies $\sum\left(1-\left|a_{n}\right|\right)^{\alpha}<\infty$ for all $\alpha>1 / 2$.

\section{REFERENCES}

1. O. Frostman, Sur les produits de Blaschke, Kungl. Fysiogr. Sällsk. i. Lund Förh., 12 No. 15, (1942).

2. W. K. Hayman, On Nevanlinna's second theorem and extensions, Rend. Circ. Mat. Palermo, Ser. II, II (1953).

3. O. D. Kellogg, Harmonic functions and Green's integrals, Trans. Amer. Math. Soc., 13 (1912).

4. P. B. Kennedy, On a theorem of Hayman concerning quasibounded functions, Canad.

J. Math., 11 (1959).

Received January 1, 1979. UNIVERSITY OF WISCONSIN MADISON, WI 53706 



\title{
PACIFIC JOURNAL OF MATHEMATICS
}

\section{EDITORS}

DONALD BABBITT (Managing Editor)

University of California

Los Angeles, CA 90024

\section{HUGO RossI}

University of Utah

Salt Lake City, UT 84112

C. C. MOORE and ANDREW OGG

University of California

Berkeley, CA 94720

\section{J. DUGUNDJI}

Department of Mathematics University of Southern California Los Angeles, CA 90007

R. FINN and J. Milgram

Stanford University Stanford, CA 94305

\section{ASSOCIATE EDITORS}
E. F. BECKENBACH
B. H. NeUmanN
F. WOLF
K. YosHIDA

\section{SUPPORTING INSTITUTIONS}

\author{
UNIVERSITY OF BRITISH COLUMBIA \\ CALIFORNIA INSTITUTE OF TECHNOLOGY \\ UNIVERSITY OF CALIFORNIA \\ MONTANA STATE UNIVERSITY \\ UNIVERSITY OF NEVADA, RENO \\ NEW MEXICO STATE UNIVERSITY \\ OREGON STATE UNIVERSITY \\ UNIVERSITY OF OREGON
}

\author{
UNIVERSITY OF SOUTHERN CALIFORNIA \\ STANFORD UNIVERSITY \\ UNIVERSITY OF HAWAII \\ UNIVERSITY OF TOKYO \\ UNIVERSITY OF UTAH \\ WASHINGTON STATE UNIVERSITY \\ UNIVERSITY OF WASHINGTON
}

The Supporting Institutions listed above contribute to the cost of publication of this Journal, but they are not owners or publishers and have no responsibility for its content or policies.

Mathematical papers intended for publication in the Pacific Journal of Mathematics should be in typed form or offset-reproduced, (not dittoed), double spaced with large margins. Please do not use built up fractions in the text of the manuscript. However, you may use them in the displayed equations. Underline Greek letters in red, German in green, and script in blue. The first paragraph or two must be capable of being used separately as a synopsis of the entire paper. Please propose a heading for the odd numbered pages of less than 35 characters. Manuscripts, in triplicate, may be sent to any one of the editors. Please classify according to the scheme of Math. Reviews, Index to Vol. 39. Supply name and address of author to whom proofs should be sent. All other communications should be addressed to the managing editor, or Elaine Barth, University of California, Los Angeles, California, 90024.

50 reprints to each author are provided free for each article, only if page charges have been substantially paid. Additional copies may be obtained at cost in multiples of 50 .

The Pacific Journal of Mathematics is issued monthly as of January 1966. Regular subscription rate: $\$ 84.00$ a year (6 Vols., 12 issues). Special rate: $\$ 42.00$ a year to individual members of supporting institutions.

Subscriptions, orders for numbers issued in the last three calendar years, and changes of address should be sent to Pacific Journal of Mathematics, P.O. Box 969, Carmel Valley, CA 93924, U.S.A. Older back numbers obtainable from Kraus Periodicals Co., Route 100, Millwood, NY 10546.

PUBLISHED BY PACIFIC JOURNAL OF MATHEMATICS, A NON-PROFIT CORPORATION

Printed at Kokusai Bunken Insatsusha (International Academic Printing Co., Ltd.). 8-8, 3-chome, Takadanobaba, Shinjuku-ku, Tokyo 160, Japan.

Copyright (C) 1979 by Pacific Journal of Mathematics Manufactured and first issued in Japan 


\section{Pacific Journal of Mathematics}

\section{Vol. 83, No. $2 \quad$ April, 1979}

Patrick Robert Ahern, On a theorem of Hayman concerning the derivative of a

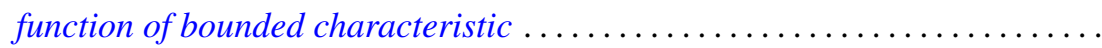

Walter Allegretto, Finiteness of lower spectra of a class of higher order elliptic

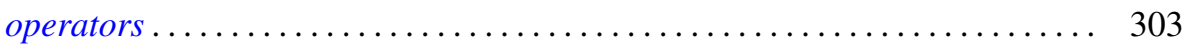

Leonard Asimow, Superharmonic interpolation in subspaces of $C_{c}(X) \ldots \ldots 11$

Steven F. Bellenot, An anti-open mapping theorem for Fréchet spaces . . . . . . . 325

B. J. Day, Locale geometry. . . . . . . . . . . . . . . . . . . . . . . . . . 333

John Erik Fornaess and Steven Krantz, Continuously varying peaking

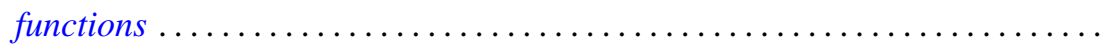

Joseph Leonide Gerver, Long walks in the plane with few collinear points ......

Joseph Leonide Gerver and Lawrence Thom Ramsey, On certain sequences of

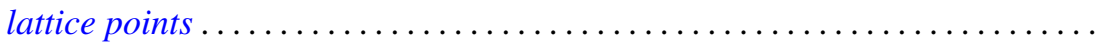

John R. Graef, Yuichi Kitamura, Takaŝi Kusano, Hiroshi Onose and Paul Winton

Spikes, On the nonoscillation of perturbed functional-differential

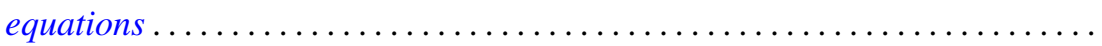

James A. Huckaba and James M. Keller, Annihilation of ideals in commutative

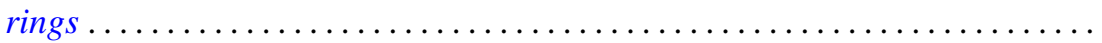

Anzelm Iwanik, Norm attaining operators on Lebesgue spaces . . . . . . . . . . .

Surjit Singh Khurana, Pointwise compactness and measurability . . . .......... 387

Charles Philip Lanski, Commutation with skew elements in rings with

involution.

Hugh Bardeen Maynard, A Radon-Nikodým theorem for finitely additive bounded

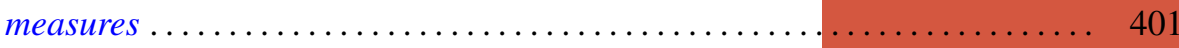

Kevin Mor McCrimmon, Peirce ideals in Jordan triple systems ..

Sam Bernard Nadler, Jr., Joseph E. Quinn and N. Stavrakas, Hyperspaces of compact convex sets.

Ken Nakamula, An explicit formula for the fundamental units of a real pure

sextic number field and its Galois closure ............

Vassili Nestoridis, Inner functions invariant connected components . .

Vladimir I. Oliker, On compact submanifolds with nondegenerate parallel

normal vector fields.

Lex Gerard Oversteegen, Fans and embeddings in the plane.

Shlomo Reisner, On Banach spaces having the property G.L

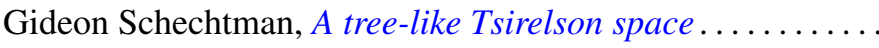

Helga Schirmer, Fix-finite homotopies . . . . . . . . . . . .

Jeffrey D. Vaaler, A geometric inequality with applications to linear forms . .

William Jennings Wickless, $T$ as an $\mathscr{G}$ submodule of $G$.....

Kenneth S. Williams, The class number of $Q(\sqrt{-p})$ modulo 4 , for $p \equiv 3$ (

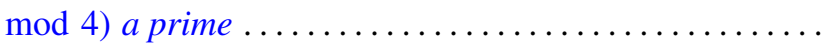

